Percutaneous endoscopic gastrostomy (PEG) feeding has become a well-established method of enteral feeding. Many patients undergo long-term feeding and require tube changes during this period. The preferred method of button-PEG tube replacement is via the endoscopic route, which requires the endoscope to be passed twice. Patients are sedated relatively heavily and re-intubation can be difficult. We describe a simple and reliable method of combined bumper and PEG tube removal.

Following intubation, the old PEG tube is grabbed with a snare. Once secure, the tube is cut a few centimetres from the skin surface and a silk thread is inserted through it (Figure $\mathbf{1}$ ). The thread is secured from the outside with a plastic introducer, used as a bung, that is pushed alongside it into the tube (Figure 2 ). This introducer comes as part of standard Fresenius PEG sets (Fresenius Kabi, Bad Homburg, Germany), but can be custommade from appropriately sized plastic tubing. The old PEG tube is removed through the oesophagus, together with the thread, which is then used to insert the new PEG tube in the usual way. The potential problem of losing the plastic introducer during retrieval has not arisen in

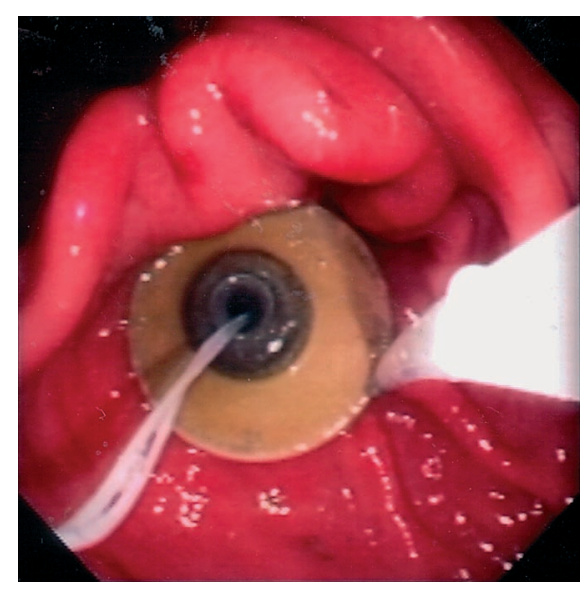

Figure 1 The silk thread is seen entering the stomach through the old PEG tube. A snare is positioned around the PEG tube and closed tightly.

\title{
A Reliable Method of Single-Pass Endoscopic Gastrostomy Replacement
}



Figure 2 The silk thread is secured with a plastic bung which is pushed tightly alongside the thread into the lumen of the old PEG tube. The old PEG tube and the thread are then pulled out through the oesophagus and the thread is used to pull the new PEG tube into place.

our experience, but if this did happen the introducer is small enough to pass through the gastrointestinal tract without causing problems.

A number of alternative techniques for replacing PEG tubes have been described, including: "crosswise" snaring of the bumper and guide wire, pushed through the old PEG tube [1]; tight snaring of the old tube and passing of a soft-tipped guide wire through it [2]; complex internal knotting of the guide wire with a snare [3]; and suturing of a guide wire to the external lumen of the old PEG tube [4]. These methods are either unreliable, complex, possible only when using particular PEG tubes, or they require additional equipment. We believe that the method described by us is the simplest and most reliable method of endoscopic PEG replacement and would recommend it as a standard approach for this procedure.

\section{B. Frenz, P. Heinsohn, G. Siuda,}

S. P. L. Travis

Department of Gastroenterology,

John Radcliffe Hospital, Oxford, UK.

\section{References}

${ }^{1}$ Malik A, Epstein A. Endoscopic replacement of PEG. Gastrointest Endosc 1994; 40: $393-394$
2 Blosser A, Stark M, Fishbeyn V, Lewis J. Simplified method of endoscopic PEG replacement. Gastrointest Endosc 1992; 38: 398

${ }^{3}$ Javaid B, O'Toole PA. Percutaneous endoscopic gastrostomy replacement: a simple secure technique for combined bumper and wire retrieval. Endoscopy 2000; 32: S65

${ }^{4}$ Wong CKM, Edwards AT, Kini US, Rees BI. A simple technique for changing percutaneous endoscopic gastrostomy tubes. J Pediatr Gastroenterol Nutr 1996; 23: 334

\section{Corresponding Author}

\section{B. Frenz, M.D.}

Department of Gastroenterology John Radcliffe Hospital

Headley Way

Headington

Oxford OX3 9DU

UK

Fax: $\quad$ +44-1865-220933

E-mail: mfrenz@doctors.org.uk 